\title{
Federalism and Entrepreneurship: Explaining American and Canadian Innovation in Pollution Prevention and Regulatory Integration
}

\author{
Barry G. Rabe
}

Conventional wisdom provides an increasingly strong endorsement of far-reaching decentralization and delegation of authority to bureaucratic agents as the most likely mechanisms to attain such central environmental policy goals as pollution prevention, cross-media regulatory integration, and development of reliable measures of environmental outcomes. Canada would appear an unusually fertile context for such innovation, given its far-reaching deference to individual provinces and their environment ministries in environmental policy. Comparative analysis of select subnational governments in Canada and the United States suggests that the states in general are far ahead of their provincial counterparts in most of these areas of innovation. Despite all the opprobrium heaped on the American environmental policy system, a combination of federal policy tools and state policy entrepreneurship appear to contribute directly to this innovation in some states and are almost completely absent in the Canadian system. These findings suggest a need for careful study of the mix of intergovernmental policy tools and principal-agent relations most likely to realize desired environmental policy goals.

Bashing the American federal government approach to environmental policy has become an increasingly popular activity for scholarly and journalistic analysts in recent years. These extremely negative accounts take numerous forms but tend to accentuate two particularly severe alleged shortcomings. First, the American system is perceived to suffer from excessive national governmental influence. The widely noted reference to the federal "gorilla in the closet" commonly is laced with assertions that the gorilla is on the rampage and out of control. Consequently, Congress drafts overly complex, command-and-control legislation that thwarts creative and effective policy implementation. Second, the U. S. Environmental Protection Agency (EPA) commonly is alleged to suffer from every conceivable sort of bureaucratic pathology. If not humbled and micromanaged by an overeager and fragmented Congress, the agency is seen as overzealous in its own right. As a result, state, local, and industry initiatives consistently are deterred by a central bureaucracy preoccupied with strict rule adherence and turf protection.

Analysts have been somewhat less exacting with reform proposals, although these have tended to flow directly from the central criticisms. A growing theme in environmental policy analysis has been advocacy for far-reaching decentralization. State, local, and regional authorities increasingly are depicted as more capable and innovative than their central-level counterparts. Indeed, in some areas of analysis, such as the growing body of scholarship on protection of "common-pool resources," it appears that subnational units can do little wrong and national units can do little right. In turn, other analysts call for a more Europeanstyle approach to environmental policy, with more generalized national legislation 
that affords far more latitude to agencies and gives them license to negotiate creative and consensual agreements with regulated parties.

Surprisingly, such analysts have tended to pay remarkably little attention to an American neighbor that clearly exhibits the sorts of qualities so often found lacking in the United States. Canada operates one of the most decentralized forms of environmental policy of any Western nation. It eschews most of the American intergovernmental tools of preemption, transfer grants, and exacting medium-based legislation in favor of what political scientist F. L. Morton has described as "de facto provincial primacy" (Morton, 1996, p. 50). Unlike their American counterparts, Canadian provinces largely are free to respond to localized conditions and to pursue innovative, flexible approaches to environmental protection. At the same time, Canadian environmental agency officials retain far more latitude from elected principals, facing few of the legislative mandates, deadlines, hammers, and oversight reviews so common in the United States. Freed from the shackles of exacting, American-style legislation and formal procedural requirements, Canadian bureaucrats should be well positioned to devise "win-win" strategies that achieve significant environmental gains at reasonable economic cost.

This analysis is intended, along with other articles in this symposium, to begin to fill the void in comparative Canadian-American environmental policy research and to explore the respective capacities of these distinctive systems. In particular, it examines the response of Canadian and American environmental policy to challenges that commonly have been raised in both nations and elsewhere. Given the penchant for regulatory fragmentation, which nation has made the most progress in integrating regulatory tools such as permitting to reduce cross-media transfers and minimize undisclosed emissions? Given the concern over the prevalence of pollution "control" approaches that attempt to contain pollutants after generation, which nation has taken the most significant steps toward developing meaningful systems of pollution "prevention"? Given the historic paucity of reliable and accessible evidence on pollutant levels and releases, particularly those toxic substances deemed to pose the greatest threat to public health, which nation has come farthest in developing information disclosure systems to inform the citizenry and provide more reliable data to guide policy? Given doubts over the trends of environmental quality and the relative impact of policy on emission levels, which nation has made the most progress in developing measures of environmental "outcomes" and demonstrating reduced levels of toxic releases to air, land, and water?

The conventional wisdom in many environmental policy circles in all likelihood would hypothesize that Canada should be substantially advanced beyond the United States in all four areas. Comparable levels of economic development and public concern over environmental issues would suggest a common footing for environmental protection efforts, bringing into advantage Canada's perceived virtues of decentralization and bureaucratic delegation (Lipset, 1990). However, this analysis of the past decade of experience in the two nations, particularly in four distinct Canadian provinces (Alberta, Manitoba, Newfoundland, and Ontario) and four distinct American states (Arizona, Minnesota, New Jersey, and Oklahoma), suggests the contrary. ${ }^{1}$ Despite remarkably common patterns of problem recognition of each of these four areas by a host of think tanks, governmental commissions, roundtables, and policy analysts on both sides of the 49th parallel, the United States has been much more active and effective in devising innovative policy approaches. Consequently, this analysis concludes that, at least in our sample jurisdictions, the United States is clearly "ahead" of 
Canada in cross-media permit integration, pollution prevention, disclosure of information on toxic substances, and achieving greater refinement and use of environmental outcome indicators.

Ironically, this analysis will suggest that the two factors that theoretically should give Canada the edge over the United States appear to work in the opposite direction. This is not to suggest that the United States somehow has resolved all of its institutional and environmental problems and now operates a smooth-running regulatory process that eliminates cross-media transfers and fosters pollution prevention at every turn. Indeed, dramatically varying degrees of progress are evident in differing American state jurisdictions. Nor is it to suggest that Canada has made no progress whatsoever in these areas. Nonetheless, this comparative case analysis finds striking and consistent differences that run counter to the prevailing views that decentralization and bureaucratic discretion are unalloyed virtues in environmental policy.

\section{The Role of Federalism}

The underlying premise behind most proposals to decentralize environmental policy is its presumed capacity to unleash creative, "bottom-up" energies, but Canada's three-decade experiment with widespread delegation of most environmental functions to its provinces reveals little subnational innovation. Instead, most provinces adhere to medium-based, pollution control-oriented regulatory systems constructed in the 1970s, appear eager to bend existing regulations to satisfy the overriding imperative of economic development, provide minimal enforcement or monitoring of regulated parties, and engage in minimal policy learning or idea diffusion with neighboring provinces or the federal government.

Unlike the United States, it is difficult to discern a significant federal presence in many key areas of Canadian environmental policy. Ottawa has established a variety of national legislation, but most decisions on standards, permitting, monitoring, inspection, and enforcement are left to its subnational units. As one Industry Canada official has observed, "Canada may have its version of the American federal gorilla in the closet, but the beast may well die from lack of oxygen." This timidity is attributable to a variety of factors, including constitutional delegation of much authority over natural resources and commerce to provinces, enduring federal reluctance to alienate more independently minded provinces such as Quebec and Alberta, and the substantial physical areas of most provinces that serve to limit direct cross-boundary conflicts. In response, most provinces have developed their own, medium-based systems of pollution control. Standards vary significantly across provinces, and although there is no evidence to indicate formal "races-to-the-bottom" provinces clearly are reluctant in any way to alienate industries that might transfer investments to less-rigorous provinces. As one provincial official noted, "the bottom line is not environmental protection here, but economic development" (Harrison, 1996, p. 137).

The economic development imperative is evident through review of each of the four provincial cases. Provincial officials and official documents talk frequently and positively about the need for pursuing greater integration across medium boundaries, promoting pollution prevention, and developing more thorough and reliable measures of environmental quality and outcomes. In addition, provinces have initiated an unending array of roundtables, commissions, 
conferences, and study groups to explore such alternatives (Doering, 1993). However, in practice, they emphasize consistently the impediments to the realization of such goals, often noting resource scarcity, excessive complexity, and a reluctance to act unilaterally and to alienate core industries that are accustomed to and content with existing arrangements. In one representative example, the province of Ontario appeared likely to make major shifts in environmental policy through the 1989 election of a New Democratic Party government that ran successfully on a platform that emphasized the need for a major overhaul of environmental policy and major new commitments to pollution prevention. However, by the end of its mandate, the government largely had abandoned promised steps and instead emphasized environmental protection as a tool of economic development, backing away from new regulatory and prevention initiatives in favor of trying to promote export of Ontario-based environmental technology and expertise (Rabe, 1997a).

A growing consensus in the literature on Canadian regulatory federalism accentuates the "buck-passing" tendencies of such a system (Harrison, 1996; Skogstad, 1996; VanderZwaag \& Duncan, 1992). This suggests a pattern whereby both federal and provincial governments attempt to take popular, symbolic steps for which it is easy to claim credit, but blame-avoidance generally prevails, with federal officials reluctant to offend provincial independence and provincial authorities reluctant to do anything that might disturb established patterns or relationships. In turn, despite the Canadian tradition of "executive federalism," which brings elected provincial and federal officials together to explore issues, there appears to be very limited serious engagement of ideas and innovations across provincial boundaries and between provinces and Ottawa. No province or provinces have emerged as Canadian pace-setters, playing the role commonly assumed in the United States by states such as California, Michigan, New Jersey, New York, Oregon, and Wisconsin, taking steps that are studied widely and emulated often by other states. Under Canadian federalism, provincial officials are far more autonomous and insulated in terms of devising alternative regulatory approaches. Indeed, provincial officials appear to be far less familiar with innovative programs in neighboring provinces than do state officials of activities in other states.

The American approach to regulatory federalism is much messier, with the federal imprint far firmer in virtually every area of environmental policy where states play some role (Scheberle, 1997). National legislation remains largely medium-based and pollution control-oriented, and relations between federal and state officials frequently are strained. Often this results in dramatic conflicts and state lamentations over perceived federal overreach; perhaps the most heavily publicized example of such conflict in recent years is the mayor of Columbus, Ohio's vigorous campaign against federal water pollution standards and his riveting example of mandatory testing for chemicals used only in growing pineapples, hardly a staple crop in central Ohio.

At the same time, some aspects of the American federal system appear to have contributed to far more regulatory integration and innovation than can be discerned in the more decentralized Canadian system. As Frank Baumgartner and Bryan Jones have noted, "the multiple venues of the states and the federal government sometimes coalesce into a single system of positive-feedback, each encouraging the other to enact stronger reforms than might otherwise occur" (Baumgartner \& Jones, 1993, p. 232). In each of the four areas examined in this article, the federal government imprint is evident in contributing to significant 
innovative steps. Contrary to the buck-pass, blame-avoid penchant of Canadian federalism, America's intergovernmental partners have been involved more actively in efforts to promote integration, prevention, information disclosure, and improved outcome measurement. In New Jersey, for example, the federal presence has been evident through an extensive series of grants to underwrite innovative state programs, the regional office of the federal EPA has supported state regulatory experiments, and newer federal legislation such as the 1990 Pollution Prevention Act has provided a clear impetus to state prevention and related efforts. Moreover, major strides in information disclosure and outcome measurement, manifest in the maturation of the Toxics Release Inventory (TRI), reflect a 15-year dialectic between federal officials and counterparts in New Jersey and other states in moving the United States toward a well-established common denominator of environmental quality that is only beginning to emerge in Canada.

Diffusion of state innovation appears to be established more firmly in the American federal system, facilitated in part by federal grants, associations, and networks linking various states and regions. Throughout American regulatory federalism, one sees far more engagement and tension between national and subnational units. It also is evident that, as in Canada, there is tremendous variation in the extent to which individual states are able or willing to design innovative programs (Lowry, 1992; Rabe, 1997b). Indeed, a number of American states, such as Oklahoma, rival Canadian provinces in accentuating economic development as their overriding environmental policy mission. Nonetheless, for all the opprobrium heaped on American regulatory federalism, there appear to be certain dynamics that facilitate innovation not detectable in its more decentralized neighbor.

\section{The Role of Agencies and Policy Entrepreneurship}

Many of the most strident critics of American environmental policy couple their concerns over a more centralized form of federalism with their perception that overzealous legislators stifle bureaucratic creativity. Commentators as diverse as Philip Howard, Stephen Breyer, Eugene Bardach, and Robert Kagan, among others, have implored legislators to cast aside prescriptive legislation and give nonelected experts the freedom to develop more flexible and effective policy (Bardach \& Kagan, 1982; Breyer, 1993; Howard, 1994). Bureaucrats presumably thus would be unleashed to work collegially and creatively with regulated parties.

In many respects, the Canadian system appears to be a well-established model for what these critics now endorse for the United States. National and provincial legislators draft relatively brief, general environmental legislation that affords enormous latitude to implementing ministries. In Alberta, for example, the 1995 Environmental Protection and Enhancement Act compressed all existing environmental statutes into a single document with 139 pages of text. It is loaded with emphases on bureaucratic discretion, making repeated use of the phrase "allows for" in authorizing numerous Alberta Environmental Protection initiatives to develop new regulatory tools that recognize "the interdependence between air, land and water." At the same time that most provincial legislation is highly delegative to ministry officials, legislative oversight of ministries is very limited and new governments usually can make very few changes in ministry leadership positions. "In most provinces, only a handful of legislators know anything about 
the environment and often environment ministers are not exactly environmental specialists," explained one former provincial official. "This means the power is in the bureaucracy and the bureaucracy can do largely what it wants."

That latitude, despite its appeal to some American critics, does not appear to translate into bureaucratic flexibility and innovation in most instances. Provincial and federal environment ministries have proven extremely reluctant to move beyond traditional measures of pollution control. In Alberta, environment ministry officials acknowledge the latitude provided by legislation but emphasize numerous resource and technical barriers that prevent deviation from conventional practice. Similar interpretations are provided in other provinces. "Several Ontario governments in the 80s and 90s have tried to move their ministry to think about things like cross-media integration and pollution prevention," recalled one former provincial environment minister:

But a new government comes in and generally has to work with the existing bureaucracy. In general, they have been there a long time and think they know better. They hunker down and resist change, do essentially what they've always done, and just wait for the government to fall and start all over again with the next one.

Many observers concur that Canadian provincial environmental officials maintain a very low public profile and are far less likely to have direct contact with legislators or interest group representatives than are their American counterparts. "We just don't see them very much," explained one individual with experience in both industry and advocacy groups:

They don't come to conferences or meetings very often, they're not part of the network that looks at options. And yet they have power. They're the ones who, when approached by a new government, talk them out of doing something new or into deferring to a committee of bureaucrats which reviews matters but concludes nothing new can be done.

This dynamic helps to explain why Canadian federal and provincial authorities tend to talk so extensively about alternatives but remain wedded to traditional approaches that are being abandoned in many parts of the United States. In contrast, American state environmental agencies not only appear to face more direct oversight from federal and state legislatures but also have experienced far more personnel turnover and have proven to be more receptive to alternative approaches than have their Canadian counterparts. In three of the four states included in this study, state policy initiatives were promoted directly from within agencies, often by officials particularly committed to a new approach and able to work effectively with such diverse constituencies as industry, environmental groups, federal officials, and state legislators.

Such "policy entrepreneurship" suggests that American agencies may be less browbeaten than conventional wisdom indicates and that they indeed are capable of devising and implementing new ideas. As political scientist Mark Schneider and colleagues note in their research on subnational policy innovation, "policy entrepreneurs tend to be 'policy generalists' who take great interest in developments outside of their own narrow area of present interest. Therefore, they are always looking for potential solutions that they may adapt into their area of current policy interest" (O'Grady \& Chi, 1995; Schneider \& Teske, with 
Mintrom, 1995, p. 48). In each of the areas examined in this paper, entrepreneurs borrowed ideas from "policy communities" that crossed state, programmatic, and disciplinary lines. In pollution prevention, for example, officials in state and federal agencies and industries tend to be highly alert to each other's efforts and interact regularly through groups such as the National Pollution Prevention Roundtable. If New Jersey begins to experiment with linking pollution prevention planning to facility-wide permitting, as it has over the past half-decade, officials from at least four other states from around the nation already have visited New Jersey to study this initiative and to consider basing their reforms on it. Such networking is facilitated further by federal efforts, including grants and information dissemination, that bring new energy to intrastate innovation and cross-state interaction.

Ironically, the greater latitude afforded Canadian bureaucrats does not appear to unleash their creative talents, freeing them instead to adhere to traditional regulatory approaches that increasingly are suspect. This is consistent with the finding that the greatest impediments to policy innovation stem from intraagency resistance (Borins, 1998). Moreover, massive cutbacks in environmental program budgets and personnel in most of the provinces in very recent years have provided further disincentive to policy innovation. Between fiscal years 1995 and 1998, environmental program expenditures in current dollars were cut $60 \%$ in Newfoundland, 43\% in Ontario, and 29\% in Alberta (Gallon, 1998). At the same time, the American environmental policy scene remains far more conflictual and indeed features numerous instances of "noninnovation." Like their Canadian provincial counterparts, several of the most active and innovative states experienced major budget and staff cuts in 1997 and 1998 that put continued pursuit of alternatives into jeopardy. Nonetheless, the comparative case findings suggest a good deal more receptivity to innovation in the American states and more capacity to move beyond lip service to actual experimentation and implementation than in Canada.

\section{Regulatory Tools: Permitting}

Both Canada and the United States have relied on common tools such as permitting and enforcement to implement environmental programs (United States Office of Technology Assessment, 1995). Permitting involves the development of formal documents that limit pollutant releases from a facility to individual environmental media and that often set specific requirements for abatement methods and reporting. Consistent with other areas of policy, permitting authority is almost completely decentralized in Canada and tends to be implemented by states with federal oversight in the United States. In both nations, permitting has been cited widely by analysts as highly fragmented and as a frequent source of cross-media pollutant transfer and duplicative requirements.

All eight jurisdictions in this study have made recent efforts to develop a more efficient permitting process. This most commonly entails more unified paper processing and technical assistance for permit applicants. Many provinces and states also are exploring expanded use of computers to provide more rapid tracking and approval of various permits. Perhaps no unit of government has gone as far in this regard as Oklahoma. Through its 1994 Uniform Permitting Act and establishment of a highly visible Customer Services Division in its Department of Environmental Quality, Oklahoma has made a massive effort to 
streamline permitting review processes. As state documents note, the agency "does not want to be placed in the position of halting or slowing a project that will bring jobs to the state" (Oklahoma Department of Environmental Quality, 1997, p. 2). The Oklahoma effort is placing concerted pressure on all officials involved with permitting to make compliance as automatic as possible. It offers numerous forms of assistance to permit applicants, particularly firms from outside the state contemplating a move to Oklahoma.

This initiative, and other more modest ones in states and provinces, indeed may accelerate permit decisions but in no way are designed to reduce crossmedia transfers or to foster pollution prevention in permitting decisions. Indeed, Oklahoma authorities have concluded that, at least for the present, taking such considerations into account is not feasible in existing permitting. Similar decisions have been reached in respective provinces, which also have concentrated their energies on permit streamlining. Environment Canada (1995, p. xxiii) encouraged provinces to examine more integrative permit reforms in the United States and elsewhere in a 1995 report, but there is no evidence that this recommendation has been followed. In provinces such as Ontario, for example, environment ministry officials repeatedly have resisted encouragement to find ways to integrate permitting across medium boundaries. Most frequently, officials have noted technical difficulties and the continuing provincial imperative of attempting to implement its 1986 water quality program, the Municipal/Industrial Strategy for Abatement (MISA), before tuming more aggressively to other media or to any form of integration. "There is an inability to think about multi-media issues in the ranks of the ministry," notes one former provincial official. "An old guard has hung on and insists nothing new can be tried until every aspect of MISA is settled." A provincial environmental group leader explained:

We know this is being tried in the States and in Europe and there is no
real industry or environmental opposition to trying integrated
permitting here. But the bureaucracy says no. They claim they sign off
on each other's paperwork and that should cover any cross-media
problems. But this isn't a system of permitting, it's plumbing by
separate medium.

Much permitting in the American system retains a "plumbing by medium" focus, but initiatives in states such as New Jersey, Minnesota, and Arizona suggest that more far-reaching efforts to achieve greater integration and procedural efficiency indeed may be possible. New Jersey has been particularly active in this regard, having launched a facility-wide permitting program as part of its far-reaching 1991 Pollution Prevention Act (Rabe, 1995). Under this law, nearly 900 New Jersey industrial facilities are required to report on annual chemical releases and specify their strategies for pollution prevention. Volunteers for facility-wide permitting agree to undergo a comprehensive facility analysis intended simultaneously to achieve greater integration and environmental improvement alongside increased procedural efficiency. Eight facilities, representing a wide range of New Jersey firms, have received such a unified permit, and nine more are scheduled to be issued before the end of 1999. Legislation is pending in the New Jersey Senate to expand this program significantly, although state budget cuts, related loss of key agency staff, and partisan conflicts have left the long-term future of the program highly uncertain. 
The first eight cases completed under this program suggest considerable ability for the facility-wide permit to discover and mitigate major cross-media transfers, significantly expand pollution prevention efforts, address previously undiscovered emission releases, and substantially increase efficiency and facility flexibility. Republican and Democratic governors alike have participated in permit-signing ceremonies and attempted to claim credit for the initiative, while industry and environmental group representatives have been very supportive. Minnesota has attempted a somewhat similar effort through its "flexible permit" program, designed particularly for facilities with complex air pollution issues. Arizona has attempted to integrate permitting with pollution prevention, and in 1997 issued its first comprehensive facility permit under the auspices of an experimental federal program.

These cases are relatively few in number but suggest considerable promise for transforming conventional environmental policy tools. All go far beyond anything being attempted in the four provinces included in this study in terms of integration across medium boundaries. In all three states, federal government input has been essential. In New Jersey, the permitting and larger prevention planning program builds on the definition of "nonproduct output" established in federal prevention legislation. This results in an assessment process that provides a far more comprehensive picture of a facility's chemical inputs and outputs than under medium-based systems. In turn, New Jersey received considerable cooperation from its regional EPA office, was able to secure a significant modification of a federal air regulatory standard that was crucial in achieving its permit integration, received technical assistance from EPA, and was the recipient of a series of federal grants that funded some of its efforts and allowed the implementing Office of Pollution Prevention to compensate medium-specific offices for "borrowing" select staff. Minnesota and Arizona have received comparable federal assistance in their recent permit efforts, and both have been heavily involved in two experimental EPA initiatives. These include Project XL, an outgrowth of the National Performance Review, which encourages state regulatory innovation and integration, and the Permit Integration Team, which supports state permit experimentation. In addition, the EPA signed National Environmental Performance Partnership agreements (NEPPs) with 40 states between 1995 and 1999, allowing participating states added flexibility in pursuing priorities and using federal grants for innovative programs.

The cases also underscore the capacity of state agency officials to work effectively as policy entrepreneurs, building supportive coalitions and amassing resources to try new approaches. In each of the three states, officials emerged who were committed to the idea of cross-media integration and who had prior experience in different areas of environmental policy. "We didn't have to change any existing federal laws to do this but a lot of effort had to come from within the agency," explained one official pivotal in the New Jersey effort:

We sought diverse, highly-motivated people to participate, people who were well-respected in specific areas and who like to ask questions. This isn't for everybody but a lot of people in the department would like to be part of this. 


\section{Pollution Prevention}

Both Canadian and American analysts of environmental policy began to concur in the 1980s that their respective systems suffered from a pollution control emphasis that often failed to consider preventive options. In Canada, Pollution Probe became particularly prominent in this area with a popular book published in 1983. In the United States, the Congressional Office of Technology Assessment emerged as a leading advocate of pollution prevention with a series of heavily publicized reports in the late 1980s. A wide array of subsequent studies and reports in both nations, provided by such groups as the International Joint Commission, the Institute for Research on Public Policy, the Rawson Academy, the World Wildlife Fund, and the National Academy of Public Administration, among others, have confirmed these initial contributions.

Common problem definition, however, has not translated into common national responses to the challenge of moving toward a more preventive approach. As in the case of integration, Canadian authorities and observers have waxed long and eloquently on the topic, but more than 15 years after the release of the Pollution Probe study very little institutional shift toward prevention is evident at either federal or provincial levels (Rabe, 1997a). In contrast, the American system remains oriented toward medium-based pollution control, but increasingly has demonstrated capacity to design new programs and instruments that begin more systematically to promote preventive strategies. These American efforts are unified by a common definition of pollution prevention and a standardized hierarchy of preferred approaches to environmental protection set forth in 1990 federal pollution prevention legislation.

Canadian federal authorities have continued to struggle for a uniform definition of pollution prevention, despite numerous high-level endorsements of the general concept. A 1994 House of Commons study and a 1995 Environment Canada study concede that Canada has made minimal progress toward establishing a common definition of pollution prevention, much less significant programmatic progress. Both reports recommend that federal and provincial officials pay greater attention to the United States and its more promising pollution prevention experiments in considering alternatives for Canada (Environment Canada, 1995; House of Commons, Standing Committee on Environment and Sustainable Development, 1994).

In theory, programs such as the 1988 Canadian Environmental Protection Act (CEPA) encourage prevention by gathering most existing programs under one legislative heading. However, this legislation has limited impact on provincial actions and has no specific mechanisms to encourage preventive approaches. The federal government did create a National Office of Pollution Prevention in 1991 to "work cooperatively with industry," and this has led to some informal collaborative efforts with specific industrial sectors. Ottawa also has established a Great Lakes Pollution Prevention Centre, located in Ontario, to disseminate information on pollution prevention opportunities, but, as one former federal official noted:

these were largely symbolic steps. In many respects, we were so embarrassed after [then EPA Administrator William] Reilly visited [in the early 90s] and we saw what the U.S. was doing, we felt we had to do something in response. So there was great pressure to get the Office 
and the Centre going, even though they have very limited staff and face huge turf resistance.

Potentially more substantial steps, such as large transfer grants to provinces, were promised but never materialized. The so-called Green Plan of 1990 was launched with great fanfare and suggested an unprecedented federal commitment to supporting and encouraging provincial environmental policy innovation, but in reality Green Plan dollars never approached initial estimates and largely were concentrated on conventional economic development strategies (Doern, 1992). Indeed, Canada has made minimal use of grants as a tool to promote provincial innovation or support for federal goals in environmental policy.

Left largely to their own devices, all of the provinces examined in this study have some official pollution prevention program. These programs most commonly emphasize technical assistance and training for industry, providing information clearinghouses, and publicizing pollution prevention "success stories." In Ontario, the Pollution Prevention Office of the Ministry of Environment and Energy has offered a "challenge" to various industries to pledge to reduce certain types of emissions, based loosely on the earlier experience of the U.S. EPA's " $33 / 50$ " program. However, these provincial programs tend to be completely voluntary and are largely isolated from other sections of provincial environment ministries. Moreover, prevention programs in Alberta, Manitoba, and Newfoundland tend to emphasize recycling and reuse far more than prevention and source reduction. Promising early efforts to promote hazardous waste reduction in Alberta and Manitoba, in conjunction with comprehensive siting efforts, have been impaired seriously by privatization of provincial waste management corporations and reclassification of large categories of hazardous waste as solid waste.

Pollution prevention appears to be beginning to move beyond these narrow parameters in at least three of the four states included in this study. Arizona, Minnesota, and New Jersey all have had statutory requirements for pollution prevention planning since the early 1990s. These involve all industrial facilities required to report their emissions under the federal TRI. Each state has established somewhat different provisions, but all generally require participants to complete an annual facility review of their pollution prevention objectives, specify intended methods to achieve reductions, and set near-term and long-term reduction goals. Planning participants also must provide formal reporting on the results of their efforts to state authorities. In Minnesota, for example, this planning process is an integral component of a much larger pollution prevention effort, which includes fees on toxic releases, specific linkages between prevention planning and other regulatory areas such as inspection and enforcement, and a series of grant and incentive programs to encourage industries to pursue prevention with vigor. In turn, New Jersey's planning efforts emphasize comprehensive "materials accounting" to examine all chemical inputs and outputs for facilities required to report, thereby setting up a requirement that each participant specify a series of numeric, 5-year goals for pollution prevention. As one analysis of this initiative concluded, such planning led participating facilities to set and achieve pollution prevention goals far beyond what could have been anticipated in the absence of such planning (Hampshire Research Associates, 1996). It also has provided an essential component in a variety of cross-media integration strategies, including facility-wide permitting. 
No two state pollution prevention initiatives are identical, yet many have derived direct and extensive support from the federal government. Whereas there is virtually no discernible relationship between federal and provincial pollution prevention activities in Canada, states such as Arizona, Minnesota, and New Jersey have relied heavily on various forms of federal assistance. One industry analyst has gone so far as to note: "The force that is really moving pollution prevention forward is the federal government" (Hanson, 1992, pp. 21-22). Unlike the Canadian Green Plan, federal grants have been essential in state pollution prevention efforts. EPA Pollution Prevention Incentives for States grants have provided substantial assistance since 1988 (Krieger, 1992), as have more recent efforts to integrate 12 distinct EPA grant programs under the auspices of the Performance Partnership Grant. A 1994 U.S. General Accounting Office report concluded that federal transfer dollars accounted for approximately $40 \%$ of total state pollution prevention expenditures and were crucial to the development and continuance of many (United States General Accounting Office, 1994). These funds have tended to prove especially crucial in those states that, unlike Minnesota, lack a direct source of prevention program funding.

The EPA also has experimented with merging pollution prevention goals with other programmatic activities. For example, EPA interpretations of the 1990 Clean Air Act Amendments increasingly involve "incorporating pollution prevention into the regulatory process" and phasing out the use of dozens of toxic chemicals (Anderson, 1994, p. 66). In addition, firms have been encouraged to take extensive prevention steps in advance of formal air regulations through the provision of "credits" under the Early Reduction Program. Furthermore, the agency increasingly is integrating compliance with prevention, using the Supplemental Environmental Projects program to mandate that firms deemed to be out of compliance with existing regulations expand pollution prevention commitments in exchange for reduced fines and penalties (Krukowski, 1993; Stahl, 1993). Perhaps most important, state officials concur that many of their current pollution prevention activities would be rendered nearly impossible in the absence of a national TRI. Indeed, more recent expansions of the initial inventory, discussed in the next section, already are yielding added data and allowing development of new tools for state officials eager to explore pollution prevention options.

As in the case of permit integration, state pollution prevention policy is influenced heavily by state agency advocates. Many of these individuals have played an active role in lobbying legislatures, securing federal and other resources, and maintaining support for their initiatives. State, federal, and industry officials with strong interests in pollution prevention represent an increasingly wellintegrated policy community, laden with policy entrepreneurs. In Minnesota, for example, such entrepreneurs were essential figures in completing reports and conducting hearings in the state capitol that set the stage for passage of the 1990 Toxic Pollution Prevention Act. Officials from the Minnesota Office of Environmental Assistance are required statutorily to report to the legislature every other year on the performance of their pollution prevention initiatives and have used these opportunities to gain publicity for specific reforms that are embraced later by the Minnesota legislature. Such entrepreneurs clearly have retained the confidence of Minnesota governors and key legislators, giving them considerable ability to direct the program, and have become leaders in national pollution prevention circles. 


\section{Information Disclosure on Toxic Releases}

A pivotal component in American progress on regulatory integration and pollution prevention has been the emergence of basic information on toxic releases to air, land, and water on an annual basis. Prior to the creation of the U.S. TRI through 1986 federal legislation, such essential information was very limited. It tended to be available only in fragmentary form, with tremendous variation from medium to medium. The federal TRI legislation was based heavily on prior experiments in Maryland and New Jersey, and the program has continued to evolve through federal scrutiny of continuing state innovation. After more than a decade of refinement and expansion, according to analysts John Brehm and James Hamilton, "TRI data have become the yardstick by which regulators, advocacy groups, industry officials, and investors judge the pollution records of manufacturing companies" (Brehm \& Hamilton, 1996, pp. 445-446). All of the states pursuing initiatives in permit integration and pollution prevention have made considerable use of these data, often relying on them to discern the extent of current releases and target the most promising areas for intervention.

In Canada, however, such an information disclosure system is in far more rudimentary stages of development. No provinces saw fit to follow the pioneering steps of Maryland and New Jersey, and the first creation of a national inventory of releases was delayed until 1993. The National Pollutant Release Inventory (NPRI) completed its first national data release in 1995, although it remains quite limited in comparison with the American system. It includes only 178 chemicals, as opposed to 595 in the United States, and has a higher release threshold that must be crossed before reporting is required. The NPRI does include a subset of facilities not required to report under the TRI, but provides far more options for exemptions and more extensive opportunities to maintain confidentiality concerning releases. Moreover, Canada has far more modest penalties for and less monitoring of facility noncompliance than the United States and thus far has achieved a very low facility compliance rate.

Perhaps more significantly, there is little evidence to suggest that either Canadian federal, provincial, or industrial authorities have begun to invest seriously in the NPRI as a potential tool to foster innovation (Environment Canada, 1995). Environment Canada devotes only two staff positions and about $\$ 1$ million (American) to processing and disseminating NPRI forms and has given little indication of pursuing the broad public distribution strategies of NPRI data so common under the TRI. This level of staff, resource, and outreach commitment is far less than many individual American states under the TRI, including three of the four included in this study. Initial Green Plan commitments to pump considerable funds into environmental information dissemination projects never approached initial dollar estimates and eschewed the NPRI in favor of more modest public information and education programs.

Moreover, there is minimal indication that any provinces have begun to consider actively how the NPRI might be used either to inform the general citizenry or to promote regulatory integration and prevention. Provincial environment ministry annual reports published in the late 1990s make virtually no reference to the first rounds of NPRI findings, much less indicate any effort to use them to guide future policy. Provincial pollution prevention programs appear completely disconnected from the NPRI to date. The four cases included in this 
study suggest that the greatest interest in the NPRI and its potential uses appears to be concentrated among national environmental interest groups, with few signs of the policy entrepreneurship within provincial agencies that has been so evident in a number of states.

While information disclosure remains in fairly primitive stages in Canada, the American TRI system continues to expand and mature. Building on the initial 1986 program, the TRI has been refined in at least four major ways. First, 1988 changes expanded TRI reporting so that participating facilities must provide a full picture of the types of treatment or containment technologies being used. "This information has been the key indicator for several federal and state pollution prevention programs," according to Minnesota pollution prevention officials (Minnesota Office of Environmental Assistance, 1996, p. 28). Second, the 1990 Pollution Prevention Act further expanded the TRI to require reporting on waste management practices and pollution prevention activities. These information sources have played an essential role in distinguishing prevention practices from treatment, recycling, and energy recovery options, and have proven especially useful in new program initiatives in states such as Arizona, Minnesota, and New Jersey. They also have provided an impetus to state hazardous waste reduction efforts. Third, in 1994, the original list of 309 chemical substances required to be reported under the TRI was expanded, with 286 additional ones. Many of these new substances are active ingredients in pesticides, making it increasingly possible that states can use TRI data to consider preventive and integrative approaches to pesticide policy. Fourth, a series of additional revisions have been made, expanding the roster of TRI reporting participants to include all federal facilities and electric power plants.

There remain many questions concerning the TRI. Even expanding the list of reported chemicals to nearly 600 still leaves gaps given the thousands of chemicals currently used industrially. There also are serious questions about the accuracy of self-reported release data, toxic materials contained in manufactured products, and the practices of those facilities not yet required to participate (Brehm \& Hamilton, 1996; Davies \& Mazurek, 1997; Malkin, Baskir, \& Spooner, 1995). Nonetheless, survey findings confirm that TRI data are receiving increasingly heavy use from environmental agencies, public interest groups, and industry. As one American industry manager noted:

TRI's mere existence has revolutionized environmental reporting. For the first time, engineers have had to scrutinize their processes as a whole and quantify releases to all media. As an investigative and measurement tool, this multimedia inventory has helped provide a baseline of certain toxics' release and, in some cases, has revealed valuable information for process improvements that otherwise might not have received adequate attention (World Wildlife Fund, 1994).

Such utilization is evident in all four of the states included in this study. Officials in Minnesota and New Jersey have made particularly aggressive use of TRI data and have taken advantage of each refinement to strengthen their own pollution prevention and integration efforts further. Virtually all of their program initiatives in these areas are predicated on the continued availability of these data. Arizona clearly is following in this path in more recent years, and Oklahoma has begun to use TRI data to chart overall environmental trends and to pinpoint major environmental problems. Perhaps most importantly, states are beginning to find 
new ways to review and evaluate the raw numbers that the TRI pours forth each year, allowing them to target problems and opportunities that otherwise might go ignored.

As in permit integration and pollution prevention, the federal role has been significant. It has developed and expanded the TRI in response to state experimentation and has made a major effort to assure widespread distribution of findings. In addition, the EPA has offered a series of grant programs to assist in the analysis and the use of TRI data. Minnesota, for example, has received federal funding support to study facility compliance with TRI requirements and to explore methods to improve compliance rates and assure enforcement. More recently, the EPA has distributed grants to Arizona, Minnesota, and New Jersey to support demonstration projects to integrate data reporting for TRI and all medium-specific programs in an attempt to develop a comprehensive environmental database for each industrial facility (Clarke, 1997).

\section{Outcomes vs. Outputs}

The evolution of information disclosure systems such as the TRI and NPRI raise the larger issue of the extent to which nations and their subnational units successfully can chart environmental quality trends and analyze areas of particular concern. Environmental policy in most Western democracies, including Canada and the United States, long has been criticized for its emphasis on "output" measures that examine the volume of work completed by an agency. Instead, contend critics, policy should attempt to develop "outcome" measures that take into account environmental performance and the attendant impact of policy instruments on those measures (Davies \& Mazurek, 1997; United States Office of Technology Assessment, 1995; Wilson, 1989).

Much of the activity in this area remains in early stages, reflected in the recent evolution of information disclosure systems, but a comparison of the provinces and states included in this analysis suggests that Canada largely remains absorbed with output analysis whereas the United States is in clear transition and making a more extensive effort to examine outcomes. In all four provinces, output measures are cited repeatedly in agency reports and emphasized in interviews. In a representative example, Newfoundland Environment annual reports list numerous activities completed by ministry staff. These include detailed measures of the total number of public addresses, responses to public inquiries and complaints, interviews, site inspections, prosecutions, license and permit approvals, studies, and memoranda completed by the ministry. Similarly, in the other provinces Canadian environmental agencies are remarkably thorough in chronicling their activity levels, and often make comparative references to show differing levels of outputs from year to year. Progress often is declared when these measures shift in preferred directions, such as increased indication of work effort. In contrast, one finds minimal provincial reference to measures of environmental quality, whether provided by the NPRI or other sources. Perhaps the biggest exception to this is efforts in some provinces, such as Alberta and Ontario, to develop measures of the health of fish and wildlife populations. Nonetheless, provincial ministries continue to emphasize output over outcome assessment.

In the four American states, a more mixed picture emerges. Regulatory streamlining has become a growing area of interest in each of the states in recent years, and has led to an expanded development of earlier output measures. In 
particular, states such as Oklahoma are putting considerable resources into examining the rate with which permits are issued and complaints resolved. This enables the Department of Environmental Quality to discover and attempt to address potential sources of delay, part of a major agency effort to accelerate every aspect of the environmental regulatory process and to ease regulatory burdens wherever possible. When coupled with continuing emphasis on measures of the numbers of permits, notices, and billings issued, among others, this gives Oklahoma a very extensive picture of regulatory outputs (Oklahoma Department of Environmental Quality, 1997).

States such as Minnesota and New Jersey have gone much farther in analyzing the TRI and other environmental outcomes data sources to provide a fuller sense of quality trends and of the role that various policies might be playing. The Minnesota Office of Environmental Assistance provides extensive and ongoing analysis, for example, of TRI data. That information not only gives a thorough account of overall Minnesota environmental trends but also allows officials to pinpoint where pollution prevention gains are-and are not-being realized. The Office also has made extended efforts to normalize all trend data to account for program and reporting changes, thereby establishing a fairly reliable baseline for comparison over time. These findings are used not just to inform the general citizenry but to tinker continually with various state programs, thereby linking outcomes data with policy reform (Minnesota Office of Environmental Assistance, 1994, 1996). New Jersey has continued to undertake similarly thorough analyses and thereby has developed an increasingly sophisticated understanding of what industrial sectors seem most responsive to pollution prevention opportunities, what impact facility-wide planning and permitting have on total facility releases and transfers, and how New Jersey compares to other comparably industrialized states and to the nation more generally (Aucott, Wachspress, \& Herb, 1996; Hampshire Research Associates, 1996). None of the provinces included in this study have any outcomes measures or assessment procedures that begin to rival those of Minnesota or New Jersey in scope or rigor.

Nationally, the TRI and NPRI remain suspect instruments for making direct comparisons on environmental quality and trends, in part for the sorts of reasons discussed above. However, initial efforts to examine releases and transfers, particularly when concentrating on common industrial sectors, jointly listed substances, and shared border regions with comparable population and industrial densities, suggest some strikingly different patterns. Most significantly, Canadian facilities appear to have a roughly comparable rate of pollutant transfer with their American counterparts but dramatically higher rates of pollutant release. In comparing the averages of all facilities and those matched by the Standard Industrial Classification (SIC) code, Canadian firms consistently release far more of their chemicals directly to the air, surface water, or land than matched American firms. In turn, American firms prove to be more responsive to the hierarchy of environmental options, transferring a much higher percentage of their chemicals to options such as recycling, reuse, recovery, treatment, and destruction (Environment Canada, 1996; United States Environmental Protection Agency, Office of Pollution Prevention and Toxics, 1997). 


\section{Conclusions}

Prevailing views on environmental policy would lead to the hypothesis that decentralization from national to subnational units and delegation from legislative principals to bureaucratic agents would unleash creative energies and policy innovation. The Canadian and American experience in fostering regulatory integration and pollution prevention, however, offers cautionary lessons. The subset of American states examined generally has made more significant steps than the subset of Canadian provinces in the areas of permit integration, pollution prevention, information disclosure, and outcomes emphasis. The more expanded federal role in the United States appears actually to have encouraged these steps rather than to have precluded them. In contrast, the absence of any significant federal role in Canada has failed to foster a comparable, much less superior, level of provincial innovation. At the same time, policy entrepreneurship appears far more likely to flourish in the American state setting than the Canadian provincial one. Entrepreneurship varies from state to state but clearly plays a role in the formation and implementation of integrative and preventive initiatives that remain much harder to discern in Canadian provinces.

This analysis is not intended to suggest that all is well in the United States and that all is ill in Canada in relation to environmental policy. Most American federal environmental legislation remains medium-based and oriented toward command-and-control strategies, placing enduring limits on innovation (Davies \& Mazurek, 1997). State government capacity and commitment in environmental policy have grown markedly in recent decades, but it remains unclear if these patterns will continue, especially if federal funds and regulatory pressures are withdrawn. In some states with impressive track records, such as New Jersey and Michigan, massive budget cuts and agency reorganizations in recent years have led to dramatic reductions of staff available to implement environmental programs or pursue entrepreneurial options. Finally, the NPRI indeed may expand and have a growing impact on integration and prevention in Canada, much as the TRI has had over the past decade in the United States. Nonetheless, these findings serve as a reminder that American environmental policy may be more flexible and creative than widely assumed and that policy options such as decentralization and delegation must be examined carefully rather than merely asserted as enduring virtues.

$* * *$

Barry G. Rabe is professor in the School of Natural Resources and Environment at the University of Michigan, Ann Arbor, MI 48109-1115. He is the author of Beyond NIMBY (Brookings, 1994) and currently is examining the subnational politics of reducing greenhouse gas emissions in American states and Canadian provinces. He also is the editor of the American Governance and Public Policy book series for Georgetown University Press.

\section{Notes}

I am grateful to the Canadian Studies Faculty Research Grant Program for financial support that was essential to conducting field research for this project. I also would like to thank David Feldman, Michael Kraft, Bill Lowry, and two anonymous reviewers for very helpful comments on 


\section{Symposium on Canadian-U.S. Environmental Policy: Rabe}

earlier versions of this article, Eden Schafer and Anne Shachoy for research assistance, and Maryellen Kouba for technical support.

1 Provinces and states were selected to maximize diversity across measures of environmental commitment and capability, consistent with Lester's (1990) categories of progressives, strugglers, delayers, and regressives, and to assure regional diversity. These cases represent a subset from a larger set of provinces and states now being analyzed. More than 60 interviews were completed in this phase of the study, including representatives of federal, regional, provincial, and state agencies, industry, and advocacy groups. All interviewees were assured that their identities would not be revealed through attribution in the text.

\section{References}

Anderson, F. R. (1994). From voluntary to regulatory pollution prevention. In B. R. Allen \& D. J. Richards (Eds.), The greening of industrial ecosystems (pp. 98-107). Washington, DC: National Academy Press.

Aucott, M., Wachspress, D., \& Herb, J. (1996). Trends in New Jersey industrial pollution prevention. Trenton, NJ: New Jersey Department of Environmental Protection.

Bardach, E., \& Kagan, R. A. (1982). Going by the book: The problem of regulatory unreasonableness. Philadelphia, PA: Temple University Press.

Baumgartner, F. R., \& Jones, B. D. (1993). Agendas and instability in American politics. Chicago, IL: University of Chicago Press.

Borins, S. (1998). Innovating with integrity. Washington, DC: Georgetown University Press.

Brehm, J., \& Hamilton, J. T. (1996). Noncompliance in environmental reporting: Are violators ignorant, or evasive, of the law? American Journal of Political Science, 40(2), 444-477.

Breyer, S. (1993). Breaking the vicious circle: Toward effective risk regulation. Cambridge, MA: Harvard University Press.

Clarke, D. (1997, May 5). E pluribus unum: States integrate their environmental data. State Environmental Monitor, 2(5), 24-26.

Davies, J. C., \& Mazurck, J. (1997). Regulating pollution: Does the U.S. system work? Washington, DC: Resources for the Future.

Doering, R. (1993). Canadian round tables on the environment and the economy. International Environmenial Affairs, 5(4), 355-370.

Doem, G. B. (1992). John-green-latelies: The Mulroney environmental record. In F. Abele (Ed.), How Ollawa spends: The politics of competiliveness, 1992-93 (pp. 353-376). Ottawa: Carleton University Press.

Environment Canada. (1995). Environmental protection legislation designed for the future-a renewed CEPA. Ottawa: Environmental Protection Service.

Environment Canada. (1996). Industrial releases within the Great Lakes basin: An evaluation of NPRI and TRI Data. Ottawa: Environment Canada.

Gallon, G. (1998, January). Environmental harmonization in Canada does more than it was meant to do. Canada Walch, pp. 17-19.

Hampshire Research Associates. (1996). Evaluation of the effectiveness of pollution prevention planning in New Jersey. Alexandria, VA: Hampshire Research Associates.

Hanson, D. J. (1992, January 6). Pollution prevention becoming watchword for government, industry. Chemical and Engineering News, pp. 21-22.

Harrison, K. (1996). Passing the buck: Federalism and Canadian environmental policy. Vancouver: University of British Columbia Press.

House of Commons, Standing Committee on Environment and Sustainable Development. (1994). Reviewing CEPA: The issues, no. 7. Otawa: House of Commons.

Howard, P. (1994). The dealh of common sense: How law is suffocating America. New York, NY: Random House.

Krieger, J. (1992, April 1). Pollution prevention incentives for states. Pollution Engineering, pp. 33-35.

Krukowski, J. (1993, October 15). EPA to stress pollution prevention. Pollution Engineering, pp. 8-9.

Lester, J. P. (1990). A new federalism? Environmental policy in the states. In N. J. Vig \& M. E. Kraft (Eds.), Environmental policy in the 1990s: Toward a new agenda (pp. 59-79). Washington, DC: CQ Press.

Lipset, S. M. (1990). Continental divide: The values and institutions of the United States and Canada. New York, NY: Roulledge. 
Lowry, W. R. (1992). The dimensions of federalism: State governments and pollution control policies. Durham, NC: Duke University Press.

Malkin, M., Baskir, J. N., \& Spooner, J. (1995). Issues in facility-level pollution prevention measurement. Environmental Progress, 14(4), 240-246.

Minnesota Office of Environmental Assistance. (1994). 1994 pollution prevention evaluation report. St. Paul, MN: Minnesota Office of Environmental Assistance.

Minnesota Office of Environmental Assistance. (1996). 1996 pollution prevention evaluation report. St. Paul, MN: Minnesota Office of Environmental Assistance.

Morton, F. L. (1996). The constitutional division of powers with respect to the environment in Canada. In K. M. Holland, F. L. Morton, \& B. Galligan (Eds.), Federalism and the environment: Environmental policymaking in Australia, Canada, and the United States (pp. 37-54). Westpon, CT: Greenwood.

O'Grady, D., \& Chi, K. S. (1995). Innovators in state government. In Council of State Govemments (Eds.), The book of the states, 1994-1995 edition (pp. 496-506). Lexington, KY: Council of State Governments.

Oklahoma Department of Environmental Quality. (1997). Environmental management for Oklahoma and the nation: FY96 annual report.. Oklahoma City, OK: Oklahoma Depanment of Environmental Quality.

Rabe, B. G. (1995). Integrated environmental permitting: Experience and innovation at the state level. State and Local Government Review, 27(3), 209-220.

Rabe, B. G. (1997a). The politics of sustainable development: Impediments to pollution prevention and policy integration in Canada. Canadian Public Administration, 40(3), 415-435.

Rabe, B. G. (1997b). Power to the states: The promise and pitfalls of decentralization. In N. J. Vig \& M. E. Kraft (Eds.), Environmental policy in the 1990s: Reform or reaction? (3rd ed.) (pp. 31-52). Washington, DC: CQ Press.

Scheberle, D. (1997). Trust and the politics of implementation: Federalism and environmental policy. Washington, DC: Georgetown University Press.

Schneider, M., \& Teske, P., with M. Mintrom. (1995). Public entrepreneurs: Agents for change in American government. Princeton, NJ: Princeton University Press.

Skogstad, G. (1996). Intergovernmental relations and the politics of environmental protection in Canada. In K. M. Holland, F. L. Morton, \& B. Galligan (Eds.), Federalism and the environment: Environmental policymaking in Australia, Canada, and the United States (pp. 103-134). Westpon, CT: Greenwood.

Stahl, M. M. (1993, April 1). Pollution prevention through enforcement. Pollution Engineering, pp. $45-47$.

United States Environmental Protection Agency, Office of Pollution Prevention and Toxics. (1997. February). Toxic chemicals at the U.S. Canada and U.S.-Mexico borders. Washington, DC: United States Environmental Protection Agency.

United States General Accounting Office. (1994). Pollution prevention: EPA should reexamine the objectives and sustainability of stale programs. Washington, DC: United States General Accounting Office.

United States Office of Technology Assessment. (1995). Environmental policy tools. Washington, DC: United States Office of Technology Assessment.

VanderZwaag, D., \& Duncan, L. (1992). Canada and environmental protection: Confident political faces, uncertain legal hands. In R. Boardman (Ed.), Canadian environmental policy: Ecosystems, politics, and process (pp. 3-23). Toronto: Oxford University Press.

Wilson, J. Q. (1989). Bureaucracy. New York, NY: Basic.

World Wildlife Fund. (1994). The right to know: The promise of low-cost public inventories of toxic chemicals Washington, DC: World Wildlife Fund. 